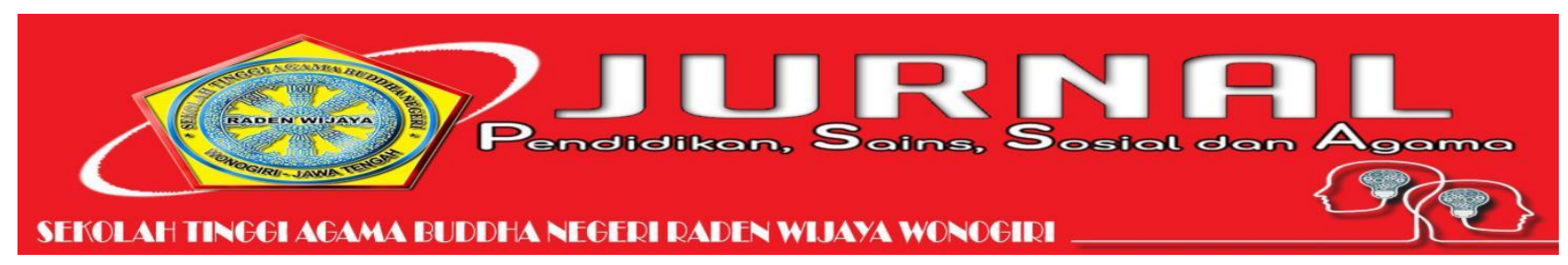

\title{
KAJIAN TERHADAP LGBT DALAM RELASI TIPITAKA PALI
}

\author{
Kabul Praptiyono, Ayu Putri Bhawanti \\ STAB Maha Prajna Jakarta
}

kabulmetta@gmail.com

\begin{abstract}
Abstrak
Penelitian ini bertujuan untuk mengetahui pandangan mengenai LGBT berdasarkan kajian umum, dan pandangan mengenai LGKBT berdasarkan kajian Tipițaka Pāli Penelitian ini menggunakan pendekatan kualitatif deskriptif, subyek penelitian adalah LGBT dan Tipitaka Pali. Teknik analisis data menggunakan model Miles and Huberman. Hasil penelitian diketahui bahwa dalam teori hukum karma Buddhis Homoseksualitas berdasarkan kamma, merupakan akibat dari perbuatan asusila pada kehidupan sebelumnya. Dalam kajian Islam Ada empat istilah fikih penting yang terkait dengan pembahasan LGBT, yaitu liwath, sihaq, takhonnuts dan tarojjul. Liwat bermakna homoseksual, Sihaq bermakna lesbianisme, takhonnuts bermakna perilaku banci, tarojjul bermakna perilaku tomboi. Semua itu dikatakan haram dan merupakan perbuatan yang tidak suci. Sedangkan gay dan lesbian itu selain dipengaruhi oleh Kamma juga dapat dipengaruhi oleh lingkungan, baik keluarga maupun masyarakat. homoseksual adalah orang-orang yang masih dapat membedakan hal-hal yang baik dan buruk, tidak menuput kemungkinan orang seperti itu lebih bijaksana daripada orang heteroseksual.
\end{abstract}

Kata Kunci: Lesbian, Gay, Biseksual, dan Transgender (LGBT), Relasi Tipitaka Pali

\begin{abstract}
This study aims to determine the views on LGBT based on general studies, and views on LGKBT based on the Tipitaka Pāli study. This research uses a descriptive qualitative approach, the research subjects are LGBT and Pali Tipitaka. The data analysis technique used the Miles and Huberman model. The results of the research show that in the Buddhist theory of the law of karma Homosexuality is based on kamma, is the result of immoral actions in a previous life. In Islamic studies there are four important figh terms associated with the discussion of LGBT, namely liwath, sihaq, takhonnuts and tarojjul. Liwat means homosexual, Sihaq means lesbianism, takhonnuts means effeminate behavior, tarojjul means tomboy behavior. All that is said to be haram and is an act that is not holy. While gays and lesbians, apart from being influenced by kamma, can also be influenced by the environment, both family and society. homosexuals are people who can still distinguish between good and bad things, not denying the possibility that such people are wiser than heterosexuals.
\end{abstract}

Key Word: Lesbian, Gay, Bisexual, and Transgender (LGBT), Tipitaka Pali Relationships 


\section{PENDAHULUAN}

Kebanyakan homoseksual (Lesbian, Gay dan Transgender) mulai menyadari dirinya mempunyai kecenderungan berbeda ketika dalam usia muda. Studi menunjukan perilaku homosexual dan ketertarikan sesama jenis banyak dijumpai sejak usia 15, di Amerika 20.8\%, UK 16.3\%, dan Amerika $18.5 \%$. Sedangkan pada kelompok wanita masing-masing $17.8 \%, 18.6 \%$, and $18.5 \%$ (Sell, 1995). Keadaan ini memperlihatkan kelompok usia sekolah adalah usia yang rentan untuk mulai terlibat dalam hubungan sesama jenis. Sedangkan keputusan untuk menjadi homoseksual kebanyakan terjadi pada usia dewasa muda (Nugroho,2010) atau pada usia ketika mereka kebanyakan menjadi mahasiswa. Akronim ini dibuat dengan tujuan untuk menekankan keanekaragaman "budaya yang berdasarkan identitas seksualitas dan gender". Kadang-kadang istilah LGBT digunakan untuk semua orang yang tidak heteroseksual, bukan hanya homoseksual, biseksual, atau transgender. Maka dari itu, seringkali huruf $\mathrm{Q}$ ditambahkan agar queer dan orang-orang yang masih mempertanyakan identitas seksual mereka juga terwakili (contoh. "LGBTQ" atau "GLBTQ", tercatat semenjak tahun 1996).

Istilah LGBT sangat banyak digunakan untuk penunjukkan diri. Istilah ini juga digunakan oleh mayoritas komunitas dan media yang berbasis identitas seksualitas dan gender di Amerika Serikat dan beberapa negara lainnya. Tidak semua kelompok yang disebutkan setuju dengan akronim ini. Beberapa orang dalam kelompok yang disebutkan merasa tidak berhubungan dengan kelompok lain dan tidak menyukai penyeragaman ini Beberapa orang menyatakan bahwa pergerakan transgender dan transeksual itu tidak sama dengan pergerakan kaum "LGB" Terdapat pula keyakinan "separatisme lesbian \& gay", yang meyakini bahwa kelompok lesbian dan gay harus dipisah satu sama lain. Selain itu, ada juga yang tidak menggunakan istilah ini karena mereka merasa bahwa: akronim ini terlalu politically correct; akronim LGBT merupakan sebuah upaya untuk mengategorikan berbagai kelompok dalam satu wilayah abu-abu; dan penggunaan akronim ini menandakan bahwa isu dan prioritas kelompok yang diwakili diberikan perhatian yang setara. Kelompok lesbian, gay, biseksual, dan transgender (LGBT) di Indonesia menghadapi tantangan hukum dan prasangka yang tidak dialami oleh warga nonLGBT. Adat istiadat tradisional kurang menyetujui homoseksualitas dan berlintasbusana, yang berdampak pada kebijakan publik. Misalnya, pasangan sesama jenis di Indonesia, atau rumah tangga yang dikepalai oleh pasangan sesama jenis, dianggap tidak memenuhi syarat untuk mendapatkan perlindungan hukum yang lazim diberikan kepada pasangan lawan jenis yang menikah. Sebagian besar wilayah Indonesia tidak memiliki hukum sodomi dan saat ini tidak mengkriminalisasi perilaku homoseksual pribadi dan non-komersial di kalangan orang dewasa, tetapi hukum di Indonesia tidak melindungi komunitas LGBT terhadap diskriminasi dan kejahatan kebencian.

Menurut Linda de Clerq, dilihat dari sudut pandang ilmu psikologi pendidikan yang dimaksud dengan tingkah laku abnormal ialah tingkah laku yang menyimpang dari norma-norma tertentu dan dirasa mengganggu orang lain. Psikologi memandang LGBT dapat timbul karena berbagai faktor dimana tidak hanya ada satu yang dapat menyebabkan seseorang menjadi LGBT.beberapa penyebab utama seseorang menjadi LGBT, diantara :

1. Faktor biologis, pengaruh genetic dan level hormone prenatal, pengalaman masa kecil dan pengalaman dimasa remaja atau dewasa berpengaruh dalam perkembangan identitas gender dan transgender.

2. Faktor lingkungan, lingkungan berperan penting bagi seseorang untuk memahami identitas seksual dan identitas gendernya. Faktor lingkungan ini terdiri atas :

a. Faktor budaya, bahwa budaya dan adat istiadat yang berlaku dalam suatu kelompok masyarakat, sedikit banyak mempengaruhi pribadi masing-masing orang dalam kelompok masyarakat tersebut. Sama halnya ketika budaya dan adat istiadat yang mengandung 
unsur homoseksualitas, maka dapat mempengaruhi seseorang menjadi seorang homoseksual dan lesbian ataupun budaya dan adat istiadat yang mengandung unsur biseksual maka dapat menyebabkan seseoran menjadi biseksual.

b. Faktor pola asuh, cara orang tua mengasuh anak dapat mempengaruhi seseorang menjadi LGBT. Anak-anak telah dikenalkan pada identitas mereka sebagai laki-laki atau perempuan sejak kecil. Pengenalan identitas diri ini tidak hanya sebatas pada sebutan namun termasuk pula penampilan fisik, pengenalan karakteristik fisik, pengenalankarakteristik sifat (laki-laki lebih menggunakan logika sedangkan perempuan lebih menggunakan perasaan).

c. Faktor figur orang berjenis kelamin sama, seorang anak pertama- tama akan melihat orang tua mereka sendiri yang berjenis kelamin sama dengan mereka, ketika proses pembentukan identitas seksual. Anak laki-laki melihat pada ayahnya dan anak perempuan melihat pada ibunya.

d. Faktor kekerasan seksual dan pengalaman traumatik kekerasan seksual, bahwa kekerasan seksual dan pengalaman traumatic kekerasan seksual yang dilakukan oleh orangorang tidak bertanggung jawab terhadap orang lain yang berjenis kelamin sama merupakan faktor yang mempengaruhi homoseksual dan lesbian.

\section{METODE}

Peneliti menggunakan metode penelitian deskriptif kualitatif karena kajian ini bertujuan untuk memperoleh pengetahuan yang lebih komprehensif dengan mendasarkan pada kajian Tipitaka maupun karya-karya ilmiah lainnya serta hasil wawancara terhadap kajian LGBT yang diungkapkan oleh peneliti sebelumnya. Penelitian ini termasuk dalam studi kasus yang berkaitan dengan suatu fenomena yang marak terjadi. Studi kasus pada kajian ini berorientasi pada fenomena LGBT yang terjadi di Indonesia maupun negara-negara tertentu. Objek dan Subjek Kajian dalam fenomena LGBT dan Pandangan LGBT berdasarkan perspektif Buddha Dhamma.

Subjek kajian difokuskan pada masyarakat guna menyikapi tindakan dan cara pandang LGBT. Sumber data dalam kajian ini terdiri atas dua sumber, antara lain sumber primer dan sumber sekunder. Sumber primer yang digunakan adalah UUD 1945 Pasal 28 "tentang HAM" dan teks-teks Buddhis dari Tipitaka seperti Vinaya Pițaka dan Sutta Pitaka. Sedangkan sumber sekunder yang digunakan adalah berupa jurnal, annual report, video, foto dari internet serta literatur mengenai fenomena LGBT di Indonesia dan sekitarnya. Metode yang digunakan untuk mengumpulkan data dalam penelitian ini adalah studi pustaka. Studi pustaka lebih difokuskan pada pencarian data dan informasi melalui dokumen berupa video, foto, berita, teks-teks dari Tipitaka, buku-buku, serta ilmu psikologi terkait dengan LGBT.

Data primer dan data sekunder yang telah terkumpul nantinya akan dianalisa untuk mendapatkan kesimpulan dengan teknik analisis isi yang bersifat mendalam. Tahapan analisis isi yang dilakukan oleh peneliti adalah sebagai berikut: Mengidentifikasi masalah berdasarkan beberapa kasus LGBT, Merumuskan masalah dengan mempertimbangkan hal-hal yang perlu dikaji dan hal-hal yang belum ada sebelumnya, Menentukan metode kajian untuk memperoleh data dari sumber primer seperti teks-teks dari Sutta Pițaka dan Vinaya Pițaka, Undang-undang hukum terkait LGBT dan sumber sekunder berupa tertulis, gambar atau video. Analisis data dilakukan dengan cara mengasosiasi 4 hal yang berkaitan dengan parenthing system, pendidikan seks dini, public awareness, dan penyadaran secara spesifik akan dikaji pada kajian Tipițaka secara mendalam dan komprehensif, seperti Donabrāhmana Sutta, Añguttāra Nikāya (V.192) mengenai hubungan seksual yang sepantasnya. Interpretasi data, hal-hal yang mengandung nilai-nilai Buddhis dipilah-pilah 
untuk dijadikan pemahaman mengenai LGBT itu sendiri.

\section{HASIL PENELITIAN DAN PEMBAHASAN}

\section{Pandangan LGBT Dalam Kajian Umum Pandangan Islam}

Pada saat Rusulullah SAW masih hidup, tidak pernah terbayangkan bahwa kaum muslim akan melakukan Homoseksual. Di masa Rusulullah SAW generasi kaum muslimin dikatakan sebagai generasi yang paling bersih, paling baik dan paling dekat dengan ketakwaan. Kaum muslimin-nya hanya mengetahui jenis maksiat ini dari $\mathrm{Al}$ Qur'an. Dalam kehidupan nyata, tidak ada laporan bahwa kaum muslimin melakukannya meski hanya satu orang. Bahkan, salah seorang khalifah Bani Umayyah yang bernama Al-Walid bin Abdul Malik tidak pernah menyangka ada pria menyetujui pria jika bukan karena ada informasi dalam $A l$ Qur'an. Ada empat istilah fikih penting yang terkait dengan pembahasan LGBT, yaitu liwath, sihaq, takhonnuts dan tarojjul. Liwat bermakna homoseksual, Sihaq bermakna lesbianisme, takhonnuts bermakna perilaku banci, tarojjul bermakna perilaku tomboi. Liwath hukumnya haram.

Ada sejumlah pendapat ulama terkait sanksi perilaku liwath, yaitu dihukum bunuh, dihukum seperti hukuman zina dan hukuman ta'zir. Bercumbu sesama lelaki yang tidak sampai ada sodomi, atau menyetubuhi anus wanita tidak termasuk liwath meskipun tetap disebut maksiat, sehingga hukuman terhadap dua jenis kriminal termasuk adalah sanksi ta'zir. Sihaq hukumannya juga haram, tetapi sanksinya tidak bisa disamakan dengan sanksi liwath. Para ulama sepakat sansi sihaq adalah ta'zir. Adapun takhonnuts dan tarojjul, keduanya juga juga perilaku menyimpang dan hukumnya haram. Sanksi terhadap dua jenis kriminal itu adalah ta'zir. Kendati demikian, imamah mukhonntas adalah sah, pernikahannya sah, penghasilannya sah, sembelihannya halal, dan boleh mengucapkan salam kepada mereka. Adapun melihat wanita ajnabi, maka mereka tidak diperbolehkan karena sunnah Nabi menunjukkan mereka harus dijauhkan dari para wanita. Persaksian mereka juga ditolak karena maksiat mereka membuat status keadilan mereka menjadi gugur.

\section{Pervensi Seksual}

Ketidakwajaran Seksual (sexual perversion) adalah perilaku seksual atau fantasi-fantasi seksual yang diarahkan pada pencapaian orgasme lewat relasi di luar hubungan kelamin heteroseksual, dengan jenis kelamin yang sama, atau dengan pasangan yang belum dewasa, serta bertentangan dengan norma-norma tingkah lau seksual dalam masyarakat yang bisa diterima secara umum. Penyimpangan seksual ini merupakan pergantian dari relasi kelamin dari heteroseksual yang bersifat kompulsif, sera tegar menetap. Karena itu disfungsi seksual dan penyimpangan seksual itu merupakan satu aspek dari gangguan kepribadian dan penyakit neurotis yang umum.

Menurut Kartini Kartono penyimpangan seksual sangat tergantung pada 1. Struktur kepribadian seseorang dan perkembangan pribadinya, 2. Menetapnya kebiasaan yang menyimpang, 3. Kuatnya tingkah laku seksual yang menyimpang, 4. Sikap pribadi individu yang bersangkutan terhadap gejala penyimpangannya, 5. Adanya sekaligus perilaku-perilaku seksual yang menyimpang lainnya, yang paralel tumbuhnya Secara klinis, tingkah laku seksual yang menyimpang (sakit, patologis, mengalami disfungsi, abnormal) itu pada umumnya berasosiasi dengan melemahnya kemampuan untuk menghayati relasi seksual dengan lawan jenis kelamin, dan biasanya ada afek- afek kuat berisikan unsur rasa-rasa, bersalahberdosa, dendam sekumat, dan kebencian.

Magolese (1970) dalam penelitiannya menunjukkan adanya perbandingan yang berbeda antara dua matabolit, androsterone dan etiocholanolone yang berbeda di antara sekelompok orang homoseks dengan kelompok heteroseks. 


\section{Pandangan LGBT Dalam Kajian Buddhis}

\section{Deskripsi Asal Mula Hubungan Seksual}

Melakukan hubungan kelamin dapat menyebabkan kelahiran seseorang anak manusia. Itulah pandangan umum yang berlaku dalam kehidupan Sudah menjadi pandangan umum bahwa kelahiran seseorang anak manusia itu adalah akibat dari hubungan kelamin sepasang manusia, lelaki dan perempuan. Karenanya dalam pandangan tradisional hubungan kelamin hanya dibenarkan dalam rangka reproduksi manusia atau pro-kreasi yang diawali terlebih dahulu oleh pasangan yang bersangkutan dengan pernikahan. Suatu ikatan bahwa tubuh perempuan yang subur itu hanya akan melahirkan anaknya dari lelaki yang menjadi pasangannya. Namun, pandangan umum bahwa hubungan kelamin menyebabkan munculnya manusia, bisa juga berlaku kebalikannya bila dilihat dalam pandangan Buddhis tentang munculnya manusia. Kemunculan manusia, seiring dengan terbentuknya bumi yang menjadi tempat penghuninya ini, juga menjadi awal atau asal mula terjadinya hubungan kelamin.

Dalam Aganna Sutta yang menjelaskan tentang munculnya bumi dan manusia itu terungkap bahwa justru dengan adanya manusia terlebih dahulu melalui proses pembetukannya seperti adanya kelamin yang menjadi dua jenis makhluk berbeda laki-laki dan perempuan, barulah kemudian muncul niat berhubungan kelamin antar sesama manusia. Kemunculan manusia menjadi awal mula hubungan kelamin. Hubungan dengan saudara sendiri (Incest) adalah suatu bentuk perzinahan, penyebab kemunduran serta merupakan tindakan seksual yang tidak sesuai Dhamma (Adhamma) seperti disebutkan dalam Digha Nikaya:

"Di antara orang-orang yang batas usia kehidupan mereka 500 tahun, ada tiga hal yang berkembang, yaitu: berzinah dengan saudara sendiri (Adhamma-Raga), keserakahan (Visama Lobhabhi Bhuta) dan pemuasan nafsu homoseksual (micchadhamma). Karena tiga hal ini berkembang maka batas usia kehidupan dan kecantikan manusia berkurang"

Para bhikku, di antara orang-orang yang batas usia kehidupan mereka 10 tahun tidak akan ada lagi (pikiran yang membatasi untuk kawin dengan) ibu, bibi dari pihak ibu, bibi dari pihak ayah, bibi dari pihak ayah yang merupakan istri dari kakak ayah atau istri guru. Dunia akan diisi oleh cara bersetubuh dengan siapa saja, bagaikan kambing, domba, burung, babi, anjing dan serigala.

\section{Homoseksual Sebagai Akibat Dari Kamma}

Homo seksual dianggap sebagai hubungan seks yang salah tetapi hubungan sek tersebut tidak termasuk semua kebiasaan seksual. Hubungan seks yang dimaksud adalah kebiasaan seksual yang merugikan diri sendiri dan orang lain. Beberapa orang menyadari seks karena tidak ingin hidup berumah tangga atau karena ingin memfokuskan diri pada perkembangan spiritual Homoseksualitas berdasarkan kamma, merupakan akibat dari perbuatan asusila pada kehidupan sebelumnya. Sedangkan gay dan lesbian itu selain dipengaruhi oleh Kamma juga dapat dipengaruhi oleh lingkungan, baik keluarga maupun masyarakat.

Manusia yang dilahirkan dengan berdasarkan Upekkhasantirana Kusalavipakacitta akan terlahir sebagai manusia cacat (cacat sejak lahir). Ada 10 (sepuluh) macam cacat, yaitu : (1) Jaccandha: mata buta, (2) Jaccabandhira: telingan tuli, (3) Jaccaghanaka : hidung cacat, (4) Jaccamaga : bisu, (5) Jaccajala : bodoh luar biasa, (6) Pandaka : banci (wadam), (7) Ubhatobayanjanaka : manusia yang mempunyai dua kelamin (perempuan dan laki-laki), (8) (9) Napumsaka : manusia yang tidak mempunyai kelamin dan (10) mamma: bicara gagap. Orang dilahirkan karena kamma buruk masa lalu seperti homoseksualitas hendaknya diterima dalam masyarakat seperti orang-orang yang lahir bisu, tuli dan buta serta cacat yang lainnya.

Orang yang lahir cacat sejak lahir tidak mutlak dipengaruhi oleh kamma buruk saja tetapi masih banyak faktor lainnya yang 
mempengaruhinya Nafsu seksual seseorang dan maksud yang melandasinya menentukan suatu hubungan bahwa seksual seseorang dianggap baik atau tidak, agama buddha menganjurkan untuk menghindari perilaku tertentu, karena perilaku yang menyimpang akan membuat seseorang dianggap aneh di dalam etika lingkungan sosial, yang berakibat pada pelarangan hukum.

Menjauhkan diri dari perilaku menyimpang akan membebaskan seseorang dari kecemasan dan rasa malu yang disebabkan oleh ketidak setujuan sosial atau ketakutan akan sangsi hukum. Homoseksualitas merupakan salah satu perilaku menyimpang. Oleh karena itu, homoseksual harus menentukan sikap sehingga dapat diterima dalam masyarakat sebagai manusia biasa bukan sebagai manusia yang dianggap aneh. Homoseksualitas seperti halnya heteroseksual muncul dari ketidaktahuan, semua bentuk sek akan meningkatkan nafsu keinginan dan ketertarikan pada tubuh. Untuk melepaskan semua ketertarikan tersebut diperlukan kebijaksanaan. Homoseksualitas tidak dianjurkan karena dapat memperlambat pembebasan diri dari samsara.

\section{Pelanggaran Seks Dalam Pandangan Buddhis}

Kedewasaan batin manusia terbagi menjadi dua, pertama kaum orang awam, putujhana yang masih bersifat dan bernafsu melekat pada hal-hal duniawi. Kedua pada Orang Suci, Asekha orang-orang yang telah lepas dari segala bentuk kemelekatan terhadap duniawi, bebas dari keinginan nafsu duniawi dan birahi. Empat tingkat golongan orang suci: Sotapañ̃na, Sakadagami, Anagami, Arahat. Adalah orang-orang yang telah mencapai tingkat kesucian memiliki batin yang cerah seperti telah bebas dari keterikatan nafsu seks dalam bentuk apapun Secara Buddhis, perilaku seks yang dianggap menyimpang adalah perilaku seks terhadap obyek seseorang yang masih di bawah pengawasan orang tuanya, para siswa di bawah bimbingan guru, selir yang di dalam kekuasaan raja, pria atau wanita dalam ikatan pasangan suami istri, orang yang menjalankan
Sila dan Vinaya serta hidup Brahmacariya Kehidupan masyarakat secara individu maupun sosial akan hina keberadaannya apabila terjadi pelanggaran pancasila buddhis, kemoralan, pembunuhan, pencurian dan perzinahan, kebohongan, serta mabukmabukan. Sabda sang Buddha: "perzinahan, melakukan sendiri, menghancurkan, mengizinkan, ini membawa orang itu akan dimusuhi lingkungan." (Angutara Nikaya, Satta Nipata: 47).

Di dalam ajaran Buddha, umat dinasehati untuk melakukan hubungan seks yang benar. Artinya, jika seseorang ingin melakukannya, haruslah tanpa melalui paksaan, kekerasan, ancaman, ataupun tindakan yang menimbulkan rasa takut. Kehidupan seks yang terhormat tidaklah bertentangan dengan agama. Agama Buddha memahami kenyataan bahwa seks diperlukan bagi yang tidak meninggalkan kehidupan duniawi. Hubungan seks dengan seseorang yang telah menikah, dikatakan bersalah karena telah melanggar norma-norma sosial yang beraku, sehingga merugikan pihak yang lain. Semua bangsa di dunia mempunyai Undang-Undang tentang penyelewengan seks. Dalam hal ini agama Buddha mendorong untuk menghargai dan mematuhi hukum di suatu negara, karena hukum dibuat untuk kebaikan masyarakat.

Di dalam Vinaya Pitaka disebutkan beberapa bentuk pelanggaran yang berkaitan dengan homoseksual atau dalam bahasa pali disebut Pandaka. Di kisah kan ketika itu seseorang Bhikkhu sedang menggosok punggung sang Upajjhaya di ruang sauna, bermaksud untuk membuat (Mani) keluar, seseorang Bhikkhu menggosoki punggung sang Upajjhaya di ruang sauna. Asucinya keluar atau asucinya tidak keluar. Muncul penyesalan dari bhikkhu tersebut maka bhikkhu itu melanggar Thullaccaya. Ketika itu seseorang Bhikkhu menyuruh orang lain mengurut-urut pahanya, bermaksud untuk membuat (mani) keluar, berkata kepada seseorang samanera, "mari, Avoso samanera, peganglah alat kelamin saya." Ia memegangi alat kelaminnya dan asusinyapun keluar. Muncul penyesalan pada dirinya. "Bhikkhu, anda telah melakukan pelanggaran 
Sanghadisesa. Ketika itu seseorang bhikkhu memegang alat kelamin samanera yang sedang tidur, asusinya keluar. Muncul penyesalan pada diri bhikkhu itu. Bhikkhu itu bukan pelanggaran sanghadisesa, melainkan pelanggaran Dukkata.

\section{Penerapan Sila Ketiga Pancasila Buddhis}

Sila ke-tiga Pancasila Buddhis Kamesumicchacara terdiri dari kata Kamma, Miccha dan cara kata Miccha berarti salah satu menyimpang dan cara berarti pelaksanaan atau perilaku sedangkan kemesu merupakan bentuk jamak dari kata kama pada kasus ketujuh menurut tata bahasa pali. Kamma berarti nafsu atau kesenangan duniawi. Kamma terdiri dari lima kesenangan indria, yaitu: (1) kesenangan indria mata, (2) kesenangan indria telinga, (3) kesenangan indria hidung, (4) kesenangan indria lidah, dan (5) kesenangan indria kulit yang merupakan permukaan jasmaniah yang merasakan sentuhan. (abhidhamma seharihari).

\section{Homoseksual Bukan Merupakan Penyakit Jiwa.}

Psikologi, psikiater, dan ahli kejiwaan yang lain sepakat bahwa homoseksualitas bukan penyakit, kekacauan mental atau problem emosional, 35 tahun penelitian ilmiah yang dirangcang secara baik dan obyektif telah menunjukkan bahwa homoseksualitas itu sendiri tidak ada kaitannya dengan kelainan jiwa, problem emosional maupun problem sosial. Homoseksual pernah dianggap sebagai penyakit kejiwaan karena ahli-ahli jiwa dan masyarakat mendapatkan informasi yang bias penelitian tentang gay, lesbian, dan bisek, dimasalalu hanya melibatkan orang-orang yang mengikuti terapi, jadi mengakibatkan kesimpulan yang biasa. Ketika penelitian menelusuri data-darta gay, lesbian, dan bisek yang tidak diikuti terapi, gagasan bahwa homoseksuallitas adalah penyakit kejiwaan ternyata salah Pada tahun 1973 asosiasi psikiater amerika menyetujui pengtingnya metode penelitan baru yang dirangcang lebih baik dengan menghapuskan homokseksialitas dari daftar resmi kekacauan jiwa dan emosional. Dua tahun kemudian asosiasi psikolog amerika mengeluarkan resulasi yang mendukung penghapusan tersebut. Selama dua puluh lima tahun akhirnya dua asosiasi ini mengdesak ahli-ahli jiwa untuk ikut membantu menghilangkan skema penyakit jiwa karena orang-orang masih mengangitkan penyakit kejiwaan dan oriantasi homoseksual.

Orang berperilaku homoseksualitas tanpaknya terlihat aneh tetapi orang tersebut tidak mengalami sakit jiwa karena orang yang sakit jiwa menurut pandangan buddhis adalah orang yang berpikirnya tidak dapat dikendalkikan dan diliputi oleh kebodohan. Orang-orang homoseksual adalah orang-orang yang masih dapat membedakan hal-hal yang baik dan buruk, tidak menuput kemungkinan orang seperti itu lebih bijaksana dari pada orang heteroseksual. Orang yang beranggapan bahwa homoseksualitas itu merupakan salah satu jenis sakit jiwa adalah orang yang hanya memperhatikan dari suatu aspek saja dan tidak mempertimbangkan aspek yang lain. Pendapat tersebut harus diperbaiki agar tidak menimbulkan kamma buruk bagi yang beranggapan seperti itu.

Di dalam Sutta pali disebutkan tegas hal-hal yang berhubungan dengan homoseksualitas sehingga dapat diasumsikan bahwa hal-hal yang berhubungan dengan homoseksualitas dapat ditelaah dengan cara yang sama dengan heteroseksual. Dalam kehidupan umat buddha orang-orang heteroseksual bukan merupakan orang yang sakit jiwa demikian juga dengan orang-orang homoseksualitas, karena orang-orang homoseksualitas berkelakuan sama dengan orang heteroseksual hanya yang berbeda pada orientasi seksnya.

\section{KESIMPULAN}

LGBT merupakan singkatan dari Lesbian, Gay, Biseksual, dan Transgender. Lesbian merupakan orientasi seksual seorang perempuan yang hanya mempunyai hasrat sesama perempuan, Gay merupakan orientasi seksual seorang Pria yang hanya mempunyai hasrat sesama Pria saja, Biseksual adalah suatu orientasi seksual terhadap pria maupun perempuan sedangkan Transgender adalah orang-orang yang identitas gendernya berbeda 
dengan organ kelamin mereka sejak dilahirkan. Dalam kajian Islam Ada empat istilah fikih penting yang terkait dengan pembahasan LGBT, yaitu liwath, sihaq, takhonnuts dan tarojjul. Liwat bermakna homoseksual, Sihaq bermakna lesbianisme, takhonnuts bermakna perilaku banci, tarojjul bermakna perilaku tomboi. Semua itu dikatakan haram dan merupakan perbuatan yang tidak suci.

Ketidakwajaran Seksual (sexual perversion) adalah perilaku seksual atau fantasi-fantasi seksual yang diarahkan pada pencapaian orgasme lewat relasi di luar hubungan kelamin heteroseksual, dengan jenis kelamin yang sama, atau dengan pasangan yang belum dewasa, serta bertentangan dengan norma-norma tingkah lau seksual dalam masyarakat yang bisa diterima secara umum. Dalam teori hukum karma buddhis Homoseksualitas berdasarkan kamma, merupakan akibat dari perbuatan asusila pada kehidupan sebelumnya. Sedangkan gay dan lesbian itu selain dipengaruhi oleh kamma juga dapat dipengaruhi oleh lingkungan, baik keluarga maupun masyarakat.

Psikologi, psikiater, dan ahli kejiwaan yang lain sepakat bahwa homoseksualitas bukan penyakit, kekacauan mental atau problem emosional, melainkan pada orientasi seksualnya yang salah. Melainkan orangorang homoseksual adalah orang-orang yang masih dapat membedakan hal-hal yang baik dan buruk, tidak menuput kemungkinan orang seperti itu lebih bijaksana daripada orang heteroseksual. Orang yang beranggapan bahwa homoseksualitas itu merupakan salah satu jenis sakit jiwa adalah orang yang hanya memperhatikan dari suatu aspek saja dan tidak mempertimbangkan aspek yang lain.

\section{Daftar Pustaka}

Altman Dennis. 2001. Global Sex Politisasi Seksual, Komersialisasi Tubuh, dan Hubungan Internasional. Jakarta: Qalam

Bodhi. 2015. The Numerical Discourses of The Buddha - Añguttara Nikāya Buku
Jilid 2. Jakarta Barat: Dhamma Citta Press.

Damayant, Rita.2015. Pandangan Mahasiswa terhadap Lesbian, Gay, Biseksual dan Transgender (LGBT) di Jakarta, Bogor, Depok Dan Tangerang, 2015. Depok: Kementerian Pemberdayaan Perempuan Dan Perlindungan Anak Pusat Penelitian Kesehatan Universitas Indonesia.

Hanno Nymous. 2016. LGBT dalam perundang-undangan kita. https://www.kaskus.co.id/thread/56dace 4a98e31b5e778b456a/lgbt-dalamperundang-undangan-kita/ di akses pada 4 februari 2020, pukul 23:12 WIB.

Kartono Kartini. 1989. Psikologi Abnormal dan Abnormalitas Seksual. Bandung: CV Mandar Maju

Rozikin Rohma Mokhamad. 2017. LGBT Dalam Tinjauan Fikih. Malang: UB Press

Silva. 2012. Homo Seksual dan Ajaran teravadha.

https://tanhadi.blogspot.com/2012/09/ho moseksual-dan-ajaran. theravada. html. Diakses pada Selasa, 4 Februari 2020, Pukul 22: 23 WIB.

Surya Satya Ronald. 2009. 5 Aturan Moralitas Buddhis. Yogyakarta: Insight Vidyasena Production.

Sugiyono. (2012). Metode Penelitian Kuantitatif Kualitatid dan $R \& D$. Bandung: Alfabeta 